\title{
A MODELAGEM VIRTUAL COMO FERRAMENTA DE DIÁLOGO ENTRE O DESIGN DE SUPERFÍCIE E O DESIGN DE MODA
}

\author{
Dailene Nogueira da Silva \\ UNESP - Campus de Bauru \\ dailenenogueira@gmail.com \\ Marizilda dos Santos Menezes \\ UNESP - Campus de Bauru \\ zilmenezes@uol.com.br
}

Resumo: O trabalho propõe o diálogo entre duas importantes vertentes da criação e produção do vestuário, o Design de Superfície e o Design de Moda, por meio da modelagem virtual. Ao desenvolver uma padronagem para tecidos o designer trabalha no campo bidimensional, porém essa superfície assumirá uma tridimensionalidade ao envolver o corpo na produção do vestuário formando um novo todo compositivo, juntamente com a modelagem, o corte, a costura e os acabamentos, sendo assim, encontra-se a necessidade do diálogo entre as duas áreas e entre os profissionais que nelas atuam. Com o objetivo de compreender melhor essa relação, o trabalho tem início com uma revisão acerca do Design de Superfície, da Modelagem e da percepção visual. Posteriormente, são ouvidos os profissionais das áreas envolvidas e realizadas experimentações em ambiente virtual, investigando como o padrão do tecido influencia no resultado final de uma peça do vestuário, com o intuito de agregar conhecimento às áreas de elaboração do produto, valorizar a técnica e a função estética do produto de moda e contribuir para ampliar o conhecimento sobre o Design de Superfície.

Palavras-chave: Design de Superfície, Design de Moda, modelagem virtual.

\begin{abstract}
This work proposes a dialogue between two important aspects of the creation and production, Surface Design and Fashion Design, through the virtual modeling. To develop a fabric pattern, the designer working in a two dimensional field, yet this surface will receive a dimensionality to involve the body in clothing production forming a new compostive all, with the modeling, the dressmaking and the finishing, therefore, it is found the need for dialogue between the two areas and the professionals who work in them. With the aim of understanding this relation, this work starts with a revision about the surface design, the modeling and the visual perception. Posteriorly are heard the professionals of the involved areas and experimentations are conducted in virtual environment exploring how the pattern influence the final result a garment piece. In order to add knowledge of the product development areas,
\end{abstract}


enhancing the technical and the aesthetic function of the fashion product and contribute to expand knowledge on the design surface.

Keywords: Surface Design, Fashion Design, virtual modeling.

\section{INTRODUÇÃO}

O trabalho do designer de superfície, na maioria das vezes, ocorre de forma anterior e independente ao trabalho do designer de moda, porém saber o produto ao qual a superfície têxtil se destina pode auxiliar e ser de fundamental importância para criação da superfície.

Ao projetar a superfície têxtil o designer trabalha no campo bidimensional, mas quando se trata do projeto para tecido, a superfície projetada assumirá caráter tridimensional ao envolver o corpo, por meio dos processos de modelagem, corte, costura e acabamentos.

A transformação da superfície bidimensional em tridimensional gera uma nova leitura da estampa, envolvendo aspectos que podem ser compreendidos por meio do estudo da linguagem e da percepção visual. A leitura da estampa pode se transformar sobre o corpo e ocasionar à roupa uma nova percepção que pode valorizar ou depreciar o produto.

Desta forma, nos deparamos com a importância do diálogo entre essas duas vertentes do projeto da vestimenta: o Design de Moda e o Design de Superfície. Aqui, a modelagem virtual é apresentada como um possível instrumento de diálogo entre essas vertentes.

Este trabalho apresenta uma síntese da dissertação desenvolvida junto ao Programa de Pós-graduação em Design da UNESP - Campus de Bauru, que procurou por meio de investigação bibliográfica, entrevistas com profissionais das áreas envolvidas e experimentações, encontrar os problemas que podem ocorrer na transformação do tecido em peça do vestuário e investigar uma possível solução para estes problemas.

O objetivo desta pesquisa foi estudar o Design de Superfícies Têxteis relacionando-o com o Design de Moda, na criação e desenvolvimento de produtos do vestuário, admitindo-se que as características e a estrutura gráfica da padronagem do tecido interferem na percepção da modelagem quando se observa a forma do produto final. Propõe-se a abordar conceitos do Design de Superfície para o Design de Moda integrando a atividade projetual da superfície têxtil com processo de criação do produto de moda.

\section{A ESTAMPA}

O termo Design de Superfície foi adotado no Brasil a partir da tradução do inglês Surface Design, por ser mais abrangente do que os que até então eram utilizados como o Design Têxtil e Desenho Industrial de Estamparia, que faziam referência somente aos projetos voltados para tecidos (RÜSTHSCHILING, 2002).

Quando nos referimos ao vestuário, a maior parte da atividade do Designer de Superfície nesta área está ligada a criação de padronagens, sejam elas obtidas por meio da tecelagem, dos processos de acabamento, ou estampadas sobre o tecido pronto. 
No que diz respeito às formas de impressão de imagens sobre o têxtil, notamos que ao acompanhar a história dos tecidos e sua evolução observa-se um avanço na qualidade e na diversidade de imagens, bem como a evolução de tecnologias e a inserção de diferentes matérias-primas.

É necessário que o designer conheça produtos e processos para eleger corretamente qual forma de produção é mais adequada ao projeto de moda, conformando produção, tempo, custos, entre outros fatores, com o resultado pretendido. De qualquer forma, os meios de produção mais rápidos permitiram uma infinidade de possibilidades não impondo limitações às criações do designer.

Desta maneira, a estampa constitui uma parte essencial do Design de Moda, diferenciando, conferindo personalidade e agregando valor à peça do vestuário, sendo que diversas marcas tratam a estamparia como elemento-chave de seus produtos, utilizando-a como fator competitivo uma vez que é rapidamente percebida pelo consumidor.

\section{A MODELAGEM}

Sobre a modelagem, podemos afirmar que é o processo que viabiliza a transformação dos tecidos, materiais planos em sua essência, em peças do vestuário adaptáveis às formas tridimensionais do corpo. Souza (2008) corrobora com a ideia afirmando que a modelagem é a técnica responsável pelo desenvolvimento das formas da vestimenta, transformando materiais têxteis em produtos do vestuário.

É também por meio do processo de modelagem que os recursos construtivos propostos pelo designer em seu projeto são aplicados a roupa, para isso é essencial ter conhecimento aprofundado das formas do corpo e de como suas medidas se transferem para as partes de um molde. Existem dois principais métodos de modelagem: a modelagem plana e a modelagem tridimensional.

A modelagem plana, também chamada de bidimensional ou geométrica, é assim denominada por usar os princípios da geometria e fundamentar-se em cálculos matemáticos. Neste método os modelos são construídos a partir de uma tabela composta por medições detalhadas dos contornos, comprimento e largura do corpo, onde as respectivas medidas serão representadas por linha horizontais e verticais e correlacionadas entre si para aproximar-se de uma reprodução fidedigna da anatomia (MARIANO, 2011).

Já a modelagem tridimensional, também conhecida como moulage, consiste na criação e produção do vestuário diretamente em uma forma tridimensional. Diferente da modelagem plana que toma as medidas do corpo como ponto de partida, a modelagem tridimensional toma o tecido como ponto inicial dispondo-o sobre o manequim e fixando-o em pontos estratégicos (DUBURG, 2012). Com o raciocínio lógico diametralmente oposto ao da modelagem plana, a moulage possibilita uma relação direta do material com a volumetria do corpo, permitindo o contato indireto com as medidas que esse corpo apresenta. Enquanto na modelagem plana decodificam-se as medidas para determinar os volumes, na tridimensional são os volumes que conduzem às medidas.

Deve-se ressaltar que essas duas formas de modelar, modelagem plana e modelagem tridimensional, não necessariamente se excluem, pois uma combinação de tecido moldado sobre o corpo por moulage e roupas sob medida é possível e amplamente utilizada atualmente. 
Ambos os processos de modelagem podem ocorrer de maneira manual ou computadorizada, neste contexto surgem os softwares de modelagem virtual. Neles é possível criar um corpo virtual com medidas predeterminadas e sobre este corpo desenhar o modelo desejado para, a partir daí, desenvolver a modelagem, planificá-la e vesti-la digitalmente, ajustando-a como se fosse em um modelo de prova (Figura 1).

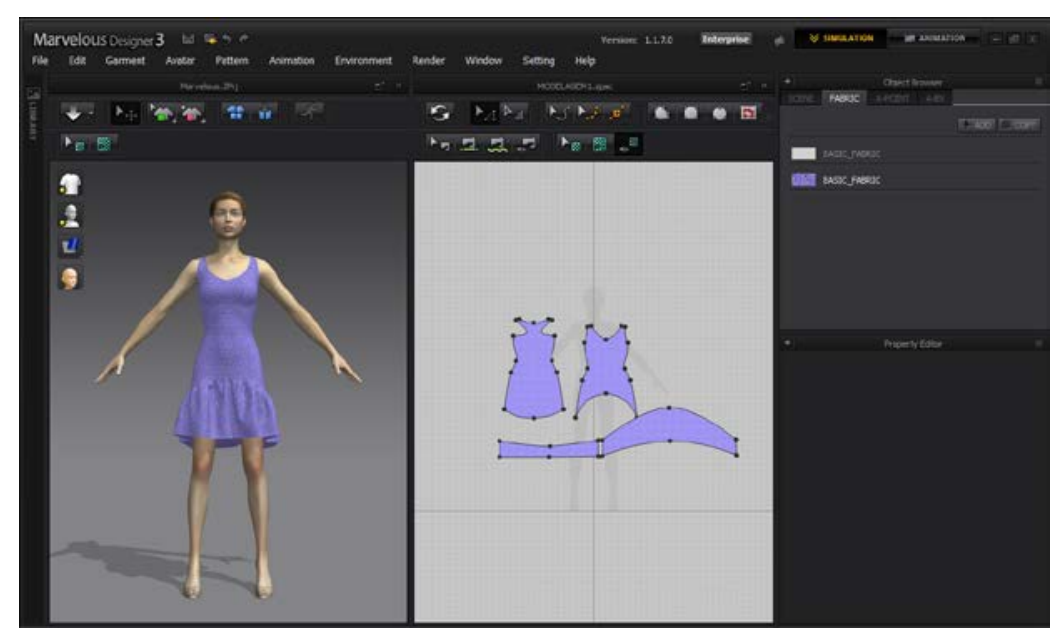

Figura 1 - Ambiente de modelagem virtual, softwares Marvelous Designer.

Fonte: Elaborado pelo autor, com base na pesquisa realizada.

Alguns desses softwares permitem aplicar a estampa sobre o tecido integrando o design da estampa na criação. Aldrich (2014) diz que "integrar o design da estampa com as partes de um molde é uma técnica que pode ser utilizada em outras atividades além da pilotagem de roupas" e afirma ainda que pode ser uma oportunidade de explorar a relação que existe entre uma imagem e a superfície em que ela será ou está aplicada.

Há no mercado softwares que permitem a impressão das estampa no formato do molde. As possibilidades de impressão da estampa no formato das partes da modelagem e prontas para a montagem são tendências importantes para peças com alto nível de encaixe, permitindo combinações precisas, desenho exclusivo e economia de tinta, pois partes restantes do tecido permanecem em branco podendo ser recicladas sem separação de cores (TRANCOSO E RÜTHSCHILLING, 2014).

A modelagem 3D por meio de softwares facilita a etapa de prototipagem das peças do vestuário, eliminado a necessidade de protótipos intermediários. A associação desta tecnologia com a estamparia digital proporciona diversas possibilidades de criação, o que significa que as peças pilotos podem ser elaboradas, avaliadas e modificadas durante o processo de desenvolvimento, conforme explica Aldrich (2014).

Desta forma surge uma importante ferramenta de auxílio na relação estabelecida entre a estampa e a modelagem do produto, uma vez que superfície e modelagem se combinam para constituir um todo compositivo na peça do vestuário, conforme discutido no próximo tópico.

\section{RELAÇÃO ENTRE SUPERFÍCIE E MODELAGEM}

Embora na maioria das vezes a atividade do designer de superfície ocorra de forma independente e anterior ao processo de criação e modelagem, uma relação é estabelecida entre ambos à medida que o tecido envolve o corpo e adquire o seu 
volume, modificando não apenas as suas características estruturais, mas também visuais. $O$ volume é obtido ao receber a aplicação dos recursos construtivos criados na concepção do modelo e executados por meio da modelagem. Sendo assim, é estabelecida a relação entre a superfície do têxtil e a modelagem.

Discutir esta relação estabelecida envolve diferentes aspectos e variados pontos de estudos, não só aqueles que tratam dos conhecimentos sobre as etapas da produção do vestuário como tecidos, criação de modelos, modelagem, costura, entre outros, mas envolve questões de cunho estético que se dedicam ao estudo de efeitos visuais e características gráficas do padrão da superfície têxtil.

A função da superfície, quando se trata do vestuário, não é apenas envolver, ela auxilia no processo de dar forma ao corpo, podendo modificar o esquema corporal e suas proporções, seja na criação de volumes ou ainda por meio dos recursos visuais quando tratamos dos padrões gráficos. $O$ estudo do design têxtil consiste em uma importante etapa do desenvolvimento de peças do vestuário, uma vez que os conhecimentos sobre as características tanto da estrutura do tecido como dos efeitos de sua padronagem, influenciará na qualidade da peça e na maneira que a roupa se comportará sobre o corpo.

Ao projetar, o designer determina as funções do produto. No caso do vestuário, a configuração do produto não é consequência somente da função prática, mas a atenção está voltada à função estética que o produto de moda deve atender. Segundo Lobach (2001) a função estética é a relação entre um produto e um usuário no nível dos processos sensoriais definindo que a função estética dos produtos é um aspecto psicológico da percepção sensorial durante seu uso. Desta forma, criar a função estética de um produto significa configurar o produto de acordo com as condições perceptivas do ser humano.

Portanto, é reforçada a ideia de que o Design de Moda deve conciliar as características materiais do produto com os valores estéticos do público ao qual se destina, uma vez que ao trabalhar as formas, silhuetas, imagens e texturas o designer produzirá, por meio de sua criação, experiências sensoriais que poderão criar percepções diversas nas pessoas. Sendo assim, passamos a estudar os elementos da linguagem visual e as teorias que tratam da percepção de forma a compreender melhor a relação estabelecida.

\subsection{Linguagem Visual}

Diversos autores tratam da linguagem visual sob pontos de vista diferentes e divergem sobre a definição dos elementos fundamentais da linguagem visual. Segundo Dondis (2000) sempre que alguma coisa é projetada e feita, esboçada e pintada, desenhada, rabiscada, construída, esculpida ou gesticulada, a substância visual da obra é composta a partir de uma lista básica de elementos visuais. Estes constituem a substância básica daquilo que vemos e são: o ponto, a linha, a forma, a direção, o tom, a cor, a textura, a dimensão, a escala e o movimento.

Lupton e Phillips (2008) acrescentam a estes elementos, outros como transparências e camadas. Gomes Filho (2004) decompõe a forma principalmente em ponto, linha, plano e volume, afirmando que o ponto evolui para a linha, esta para o plano, que se amplia para gerar o volume. Wong (2010) ainda divide e classifica tais elementos em quatro tipos: conceituais, visuais, relacionais e práticos. 
Uma importante teoria que trata da linguagem visual, especialmente no que tange a percepção visual é a Gestalt, que, segundo afirma Dondis (2000, p.51), "grande parte do que sabemos sobre a interação e o efeito da percepção humana sobre o significado visual provém das pesquisas e dos experimentos da psicologia da Gestalt". Passamos a estudá-la.

\subsection{Gestalt}

Seguindo com a investigação acerca da percepção humana, a fundamentação teórica da Gestalt afirma que não vemos partes isoladas, mas relações, uma parte na dependência de outra parte. "Para a nossa percepção, que é resultado de uma percepção global, as partes são inseparáveis do todo e são outras coisas que não elas mesmas, fora desse todo" (GOMES, 2004). O fato de o cérebro não enxergar elementos isolados, e sim o conjunto e as relações entre as partes é o que dá origem ao que chamamos de ilusão de ótica, figuras conhecidas que confundem o olhar criando imagens distintas da realidade.

A teoria da Gestalt sugere uma resposta ao porquê de umas formas agradarem mais que as outras. Considera os fenômenos psicológicos como um conjunto autônomo, indivisível e articulado na sua configuração, organização e lei interna, que não dependem da percepção individual e que formulam leis próprias da percepção humana.

Sendo a roupa e principalmente as estampas impressas sobre os tecidos uma forma de comunicação visual, estudar as leis estabelecidas pela Gestalt pode ajudar a pensar o Design de Moda e o Design Têxtil. Ao observarmos uma roupa, a padronagem e a modelagem se integram e percebemo-las como um todo.

Estudando a Gestalt observa-se que as leis da teoria assim como os estudos que tratam da comunicação visual podem ajudar a direcionar o foco de atenção e a organização de conteúdos visuais de uma forma eficaz. Podem ser consideradas ferramentas teóricas essenciais também para o design de superfícies têxteis auxiliando na compreensão do comportamento da percepção humana sobre a estampa e no entendimento da relação que cada elemento do padrão cria dentro do rapport.

Quando nos referimos ao vestuário, a Gestalt bem como o conhecimento dos elementos da linguagem visual auxiliam a compreender a percepção do todo: a composição gráfica do padrão do tecido se modifica ao ser transformada em roupa passando a fazer parte de uma nova composição, que integra fatores como o caimento do tecido, os recursos da modelagem, costura e acabamentos, formando um todo.

Investigando a teoria observa-se que é possível relacionar ambas as áreas e verificar o quanto visualmente interessante pode se tornar o resultado do diálogo entre a padronagem e a modelagem da roupa.

\section{PROCEDIMENTOS DE PESQUISA}

Além da investigação bibliográfica, já presentada, foram realizadas entrevistas com profissionais que têm seu trabalho diretamente ligado à relação investigada: designers de superfície, designers de moda, modelistas e docentes do curso de moda. Foram entrevistados 14 profissionais, no total, o propósito era que os mesmos pudessem fornecer dados ou ainda apontar caminhos para investigar a relação.

O objetivo das entrevistas foi conhecer como se estabelece a relação entre a estampa e o vestuário por meio da ótica de diferentes profissionais, tanto no dia a dia 
profissional quanto na prática acadêmica, ajudando a delimitar e conhecer como se dá, atualmente, a criação e execução de padronagens para tecidos e o emprego destes no vestuário.

As perguntas elaboradas aos docentes buscaram investigar se a relação e os efeitos das estampas na modelagem são abordados na formação do profissional de moda e de que forma se dá esta abordagem. Em se tratando de uma pesquisa qualitativa procurou-se entrevistar professores que tivessem sua atividade de docência voltada a modelagem ou ainda ao Design de Superfície uma vez que estes são os temas centrais tratados.

Ao elaborar as questões aos designers de superfície buscou-se situar o trabalho deste profissional no segmento de mercado iniciando pelas questões sobre o tempo de atuação e a área do mercado em que o profissional trabalha. As demais perguntas seguiram buscando conhecer um pouco sobre as etapas do desenho de padrões e procurando entender como o produto influencia em sua criação, procurou-se ainda conhecer a opinião do entrevistado sobre a maneira que as possibilidades técnicas interferem em seu trabalho ou ainda se há relação entre a sua criação e o produto final.

Aos designers de moda foram elaboradas perguntas com o intuito de conhecer como, na prática profissional, é resolvida a questão da estampa na criação do modelo. As questões investigavam a importância do padrão na criação e a relação entre a criação e a execução do modelo levando em consideração as estampas.

Por fim, um questionário foi elaborado ao modelista, outro profissional envolvido na questão tratada. O objetivo do questionário foi verificar como é resolvida a questão da estampa do tecido e se algum problema é encontrado por estes profissionais no seu dia a dia ao realizarem os moldes. Assim como as demais entrevistas essa também se iniciou com a pergunta sobre o tempo e a área de atuação do profissional.

De modo geral, diferentes respostas foram dadas pelos profissionais. Como pontos comuns nas respostas, podemos destacar a preocupação com a adequação do produto à padronagem, os designers de moda destacaram mais a adequação do motivo do padrão ao público alvo, enquanto os docentes e designers de superfície citaram a adequação das características das padronagens, como tamanho dos módulos, dos motivos, as cores, ao modelo.

Por parte dos modelistas as preocupações destacadas foram mais de ordem técnica, como o correto corte em relação ao fio do tecido, ou ao sentido da estampa. Da mesma forma afirmaram ser importante o conhecimento do tecido no momento da realização dos moldes. Também foi ponto comum entre as respostas a importância do processo de produção do tecido e da aplicação da padronagem sobre o tecido, sendo esta última importante principalmente aos designers de superfície.

Conhecidas as respostas dos profissionais da área, foi possível investigar como o diálogo entre o Design de Superfície e o Design de Moda, pode auxiliar na resolução de algumas das questões levantadas aprimorando o trabalho destes profissionais e do produto resultante deste trabalho. Uma diretriz apontada na pesquisa se baseou no uso dos ambientes de modelagem virtual que permitem a aplicação da estampa ao tecido já na fase de construção do modelo, permitindo a visualização do resultado final e possibilitando ao profissional analisar o todo compositivo. 


\section{MODELAGEM VIRTUAL}

Os softwares de modelagem virtual constituem uma importante ferramenta de auxílio no diálogo entre o Design de Superfície e o Design de Moda, pois permitem visualizar a interação entre o tecido e a modelagem em um protótipo virtual. Sendo possível que ajustes sejam feitos ainda nesta etapa.

O Software Marvelous Designer, usado como objeto de estudo nesta pesquisa, permite simular em ambiente virtual com bastante precisão o resultado final da roupa, uma vez que o programa possibilita que o tipo de tecido e suas propriedades sejam configurados facilitando a visualização do caimento da peça e suas características no manequim virtual.

Aldrich (2014) afirma que "os programas em 3D que criam simulações de roupas em modelos utilizam essa técnica em um nível mais avançado; a amostra pode ser vista com uma rotação em tempo real, permitindo a verificação do design da estampa de todos os ângulos".

Neste trabalho, algumas experimentações foram realizadas no software Marvelous Designer a partir dos apontamentos feitos pelos profissionais ao responder as perguntas das entrevistas bem como as questões obtidas a partir da revisão bibliográfica. Foram investigados como o software pode auxiliar na identificação e resolução de possíveis questões e problemas entre a padronagem e a modelagem da roupa.

Quanto ao ajuste do módulo, tamanho e posicionamento dentro do modelo, ao importar um padrão para o tecido de uma modelagem é possível configurar as dimensões dos módulos verificando qual o tamanho do padrão é mais adequado ao modelo e qual o efeito visual que esta padronagem agrega ao vestuário, possibilitando ao profissional idealizar e decidir sobre o resultado final antes mesmo da produção do tecido ou da roupa. $O$ ajuste também permite inverter o sentido da estampa ou ainda girá-lo de acordo com o ângulo desejado (Figura 2 e 3).

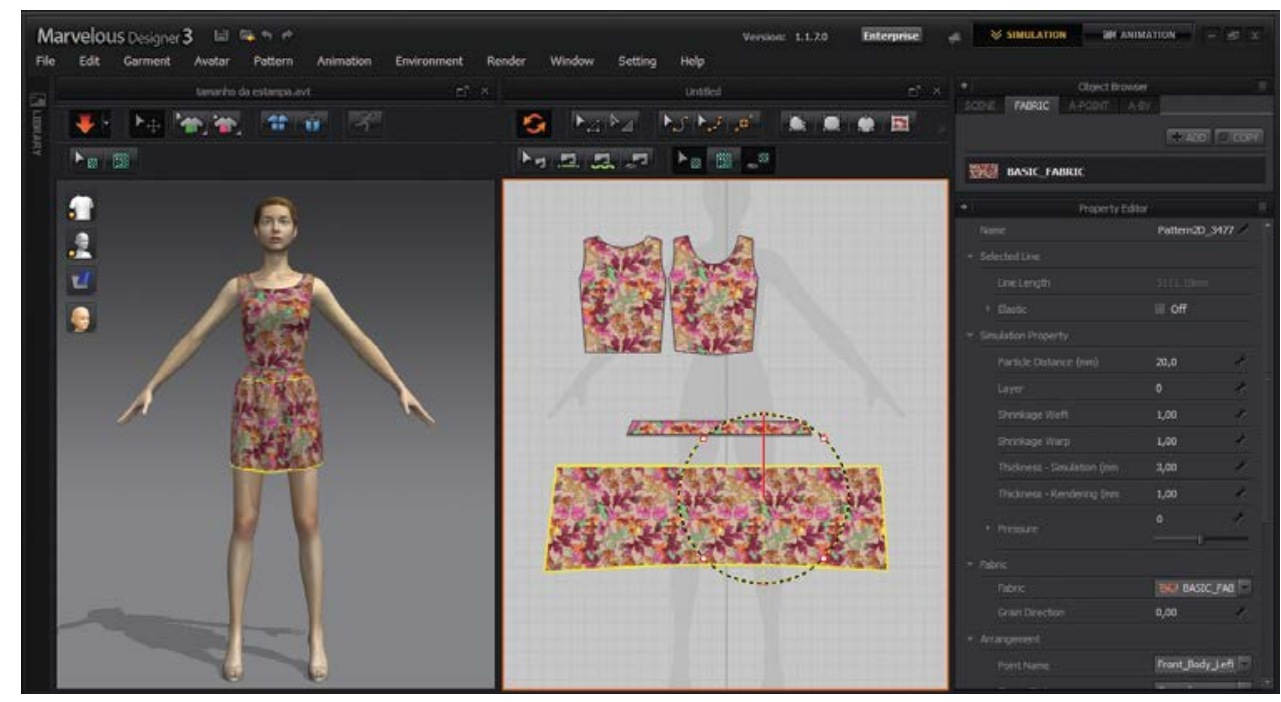

Figura 2 - Ajuste do molde à modelagem.

Fonte: Elaborado pelo autor, com base na pesquisa realizada. 


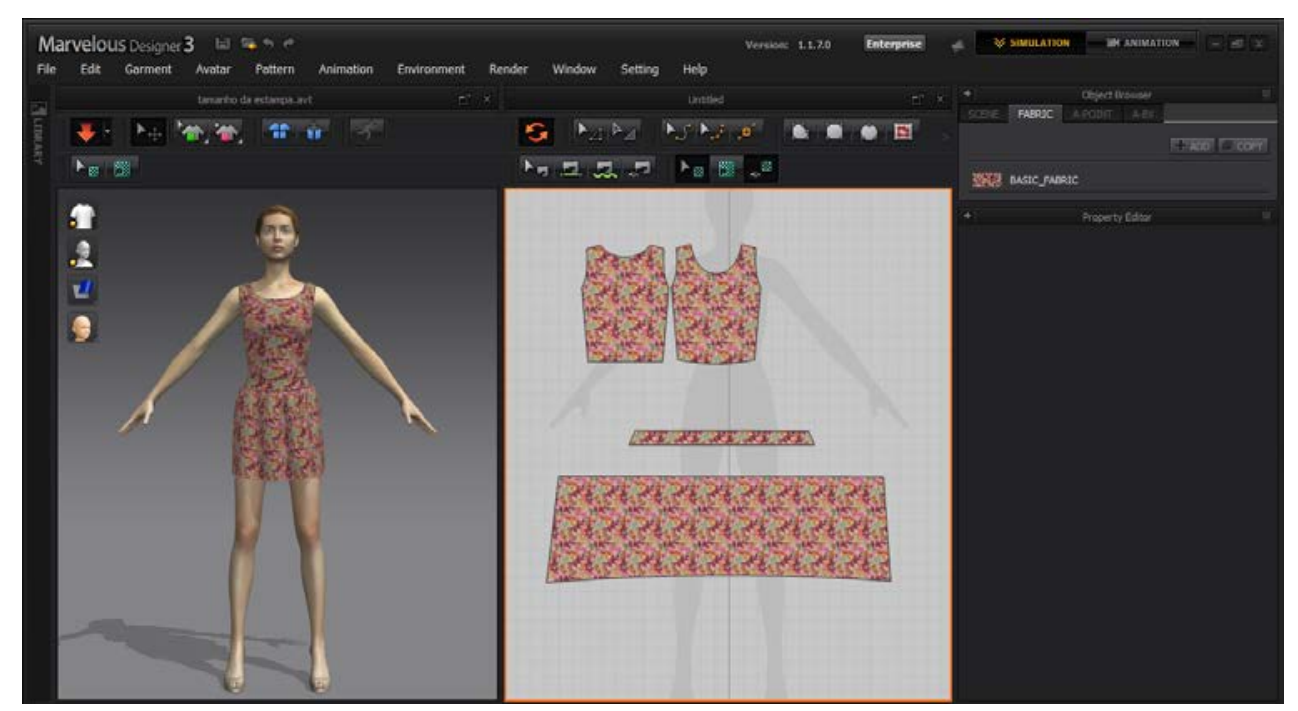

Figura 3 - Redução do módulo em relação ao modelo.

Fonte: Elaborado pelo autor, com base na pesquisa realizada.

Analisar a estampa em prototipagem, manipular tamanho dos módulos até chegar à solução que encaixe na produção, é uma das interações entre o Design de Superfície e o Design de Moda permitida pela modelagem virtual.

Outro ponto da relação que pode ser analisado é a possível distorção da padronagem, uma vez que o software permite configurar as características do tecido, como por exemplo, a elasticidade. É possível detectar já nesta etapa possíveis distorções, causadas pelas propriedades do tecido. A Figura 4 apresenta o teste feito com um padrão listrado.

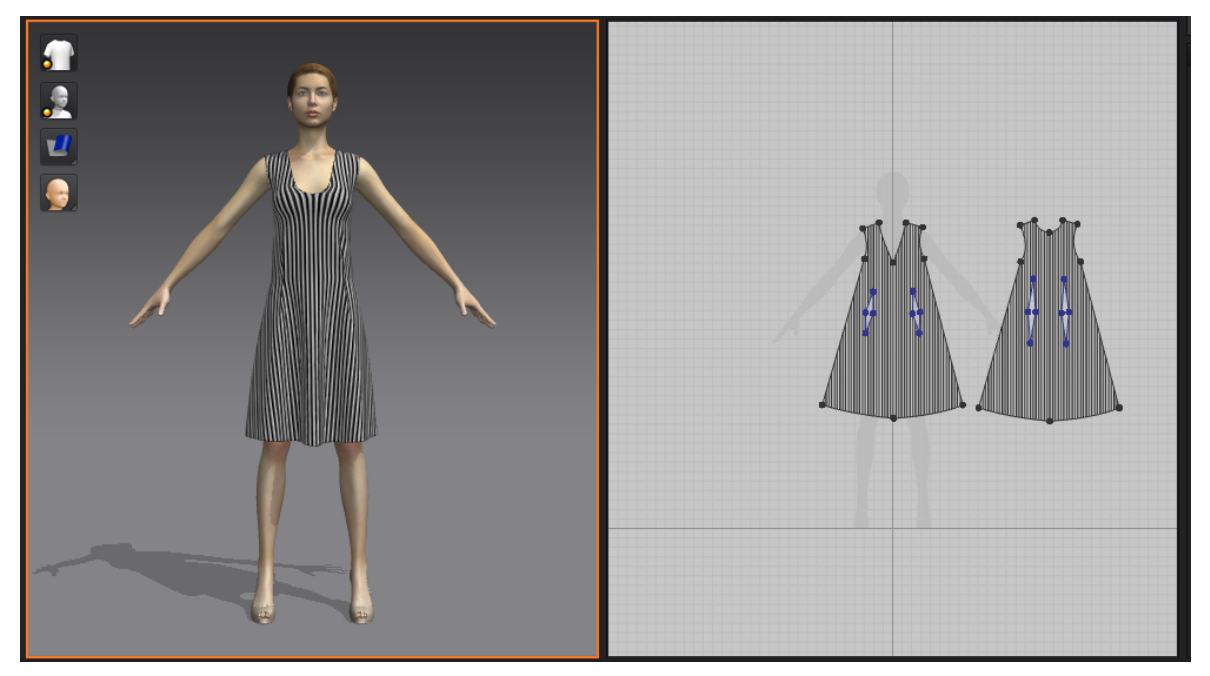

Figura 4-Distorção da padronagem.

Fonte: Elaborado pelo autor, com base na pesquisa realizada.

De acordo com as repostas de alguns profissionais e com os estudos sobre a Gestalt e a linguagem visual, observa-se que a estampa pode influenciar na percepção da silhueta quando consideramos a roupa como um todo. Neste sentido o protótipo 
virtual permite verificar o produto final e analisar se o resultado pretendido será alcançado.

Alguns dos efeitos que certos padrões causam sobre a silhueta já são conhecidos e explorados, como o caso das listras que na vertical alongam a silhueta e na horizontal produzem o efeito contrário. Ou ainda o uso de motivos grandes ou pequenos que podem expandir ou diminuir a silhueta.

Sabe-se que aliado ao uso das cores e de conceitos da comunicação visual o desenho sobre o tecido pode destacar partes do corpo ou atenuá-las por meio de suas características gráficas. A experimentação virtual auxilia para que sejam alcançados os objetivos do profissional no momento da criação.

A Figura 5 apresenta uma experimentação mostrando como o posicionamento do motivo da estampa pode modificar a percepção silhueta, aumentando os ombros ou o quadril, diminuindo a cintura, entre outras características.

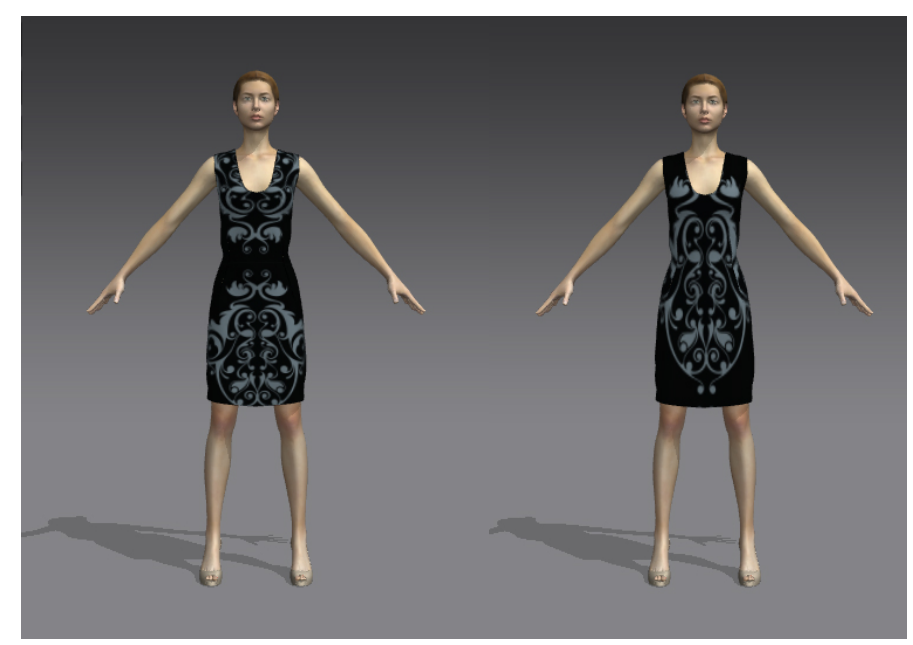

Figura 4 - Alteração da silhueta.

Fonte: Elaborado pelo autor, com base na pesquisa realizada.

Sendo assim, em cada desenho de peça para o vestuário pode-se explorar diferentes efeitos, analisando as características gráficas do padrão e o que ele agrega à modelagem. $O$ inverso também deve ser observado, uma vez que a modelagem pode agregar à estampa, criando efeitos, ressaltando ou disfarçando as características de acordo com a intenção.

\section{CONSIDERAÇÕES FINAIS}

Podemos perceber que os problemas decorrentes das relações estabelecidas entre superfície e vestuário são resolvidos na prática pelos profissionais que possuem a visão do produto final, porém, há pouca bibliografia e conhecimento teórico que tratem do assunto de forma a relacionar as duas vertentes.

Os conceitos da linguagem visual e as teorias da percepção ajudam a entender e explicitar a relação estabelecida entre a superfície e o vestuário ao analisar o todo, 0 produto final. $O$ conhecimento advindo da prática também possibilita teorizar esses conceitos, uma vez que se acredita no valor da teoria que nasce da prática produtiva, gerando assim conhecimento para quem estuda a questão.

O presente estudo sugere a comunicação entre as áreas fazendo uso dos softwares de modelagem virtual como ferramenta para esta interação. Os softwares 
ajudam a provar, por meio das experimentações, os efeitos da estampa na silhueta e como a padronagem pode servir de diferencial, valorizando o produto, ou ainda alterando sua percepção quando combinado a modelagem e a outros aspectos da produção do vestuário.

Integrar as áreas por meio do diálogo entre as vertentes do projeto proporcionam o aprimoramento, contribuindo para a valorização do produto de moda e dos profissionais envolvidos. A visão do designer de superfície aliada à do designer de moda contribuem para que os efeitos alcançados sejam os pretendidos.

Desta forma este estudo, relacionando as duas vertentes, é um passo inicial para que seja gerado conteúdo teórico para a prática e o ensino desses assuntos que, até então, não são relacionados teoricamente. $O$ assunto aqui tratado ainda deve ser discutido e ampliado, pois diversas variantes que interferem no processo podem ser apontadas, como por exemplo, as propriedades do tecido e os processos de obtenção das estampas.

\section{REFERÊNCIAS}

ALDRICH, Winifred. Modelagem Plana - Para Moda Feminina. Porto Alegre: Editora Bookman, 2014.

DONDIS, Donis A. Sintaxe da linguagem visual/Donis A. Dondis; [tradução Jefferson Luiz Camargo]. São Paulo: Martins fontes, 2000

DUBURG, Annette. Moulage: arte e técnica no design de moda/Annette Duburg, Rixt van der Tol; tradução: Bruna Pacheco. Porto Alegre: Bookman, 2012

GOMES FILHO, João. Gestalt do Objeto: Sistema de Leitura Visual da Forma. São Paulo: Escritura Editora, 2004.

LÖBACH, Bernd. Design industrial: bases para configuração dos produtos industriais. São Paulo: Edgard Blücher, 2000.

LUPTON, E.; PHILLIPS, J.C. Novos Fundamentos do Design. São Paulo: Cosac Naify, 2008.

MARIANO, Maria. Da Construção à Desconstrução: A modelagem como recurso criativo no design de Moda. Dissertação (Mestrado em Design) - Universidade Anhembi Morumbi, São Paulo, 2011.

RUTHSCHILLING, E. A. Design de Superfície: prática e aprendizagem mediadas pela tecnologia digital, 2002. Tese (Doutorado em Informática da Educação) - Faculdade de Educação, Universidade Federal do Rio Grande do Sul, Porto Alegre.

SOUZA, Patricia de Mello. A modelagem tridimensional como implemento do processo de desenvolvimento do produto de moda. 2006. 113f. Dissertação (Mestrado em Desenho Industrial) - Faculdade de Arquitetura, Artes e comunicação, Universidade Estadual Paulista. Bauru, 2007.

TRANCOSO, Samira M.K.; RUSTSCHILLING, Evelise. A Estamparia Digital e Prospecções no Uso das Tecnologias. In: Anais do 10 Coloquio de Moda - 7a Edição Internacional. Caxias do Sul, 2014. 
WONG, Wucius. Princípios da forma e desenho. Tradução Alvamar Helena Lamparelli. São Paulo: Martins Fontes, 2010. 352. 